\title{
Gene expression profiling of the human natural killer cell response to Fc receptor activation: unique enhancement in the presence of interleukin-12
}

\author{
Amanda R. Campbell ${ }^{1,2+}$, Kelly Regan ${ }^{2,3+}$, Neela Bhave ${ }^{1}$, Arka Pattanayak ${ }^{3}$, Robin Parihar ${ }^{4}$, Andrew R. Stiff ${ }^{1,2}$, \\ Prashant Trikha', Steven D. Scoville ${ }^{1,2}$, Sandya Liyanarachchi ${ }^{5}$, Sri Vidya Kondadasula ${ }^{6}$, Omkar Lele $^{3}$, \\ Ramana Davuluri ${ }^{7}$, Philip R. O. Payne ${ }^{3}$ and William E. Carson III, ${ }^{1,8,9^{*}}$
}

\begin{abstract}
Background: Traditionally, the $\mathrm{CD} 56^{\mathrm{dim}} \mathrm{CD} 16^{+}$subset of Natural Killer (NK) cells has been thought to mediate cellular cytotoxicity with modest cytokine secretion capacity. However, studies have suggested that this subset may exert a more diverse array of immunological functions. There exists a lack of well-developed functional models to describe the behavior of activated NK cells, and the interactions between signaling pathways that facilitate effector functions are not well understood. In the present study, a combination of genome-wide microarray analyses and systems-level bioinformatics approaches were utilized to elucidate the transcriptional landscape of NK cells activated via interactions with antibody-coated targets in the presence of interleukin-12 (IL-12).
\end{abstract}

Methods: We conducted differential gene expression analysis of $\mathrm{CD} 56^{\mathrm{dim}} \mathrm{CD} 16^{+}$NK cells following FcR stimulation in the presence or absence of IL-12. Next, we functionally characterized gene sets according to patterns of gene expression and validated representative genes using RT-PCR. IPA was utilized for biological pathway analysis, and an enriched network of interacting genes was generated using GeneMANIA. Furthermore, PAJEK and the HITS algorithm were employed to identify important genes in the network according to betweeness centrality, hub, and authority node metrics.

Results: Analyses revealed that $C D 56^{\mathrm{dim}} \mathrm{CD} 16^{+} \mathrm{NK}$ cells co-stimulated via the Fc receptor $(\mathrm{FcR})$ and IL-12R led to the expression of a unique set of genes, including genes encoding cytotoxicity receptors, apoptotic proteins, intracellular signaling molecules, and cytokines that may mediate enhanced cytotoxicity and interactions with other immune cells within inflammatory tissues. Network analyses identified a novel set of connected key players, BATF, IRF4, TBX21, and IFNG, within an integrated network composed of differentially expressed genes in NK cells stimulated by various conditions (immobilized IgG, IL-12, or the combination of IgG and IL-12).

Conclusions: These results are the first to address the global mechanisms by which NK cells mediate their biological functions when encountering antibody-coated targets within inflammatory sites. Moreover, this study has identified a set of high-priority targets for subsequent investigation into strategies to combat cancer by enhancing the anti-tumor activity of $\mathrm{CD}_{56}{ }^{\mathrm{dim}} \mathrm{CD} 16^{+} \mathrm{NK}$ cells.

Keywords: NK cells, CD16, Gene microarray, Interleukin-12, Interferon-gamma

\footnotetext{
* Correspondence: William.Carson@osumc.edu

${ }^{\dagger}$ Equal contributors

${ }^{1}$ The Arthur G. James Comprehensive Cancer Center and Solove Research Institute, The Ohio State University, Columbus, OH 43210, USA

${ }^{8}$ Department of Surgery, The Ohio State University, Columbus, OH 43210, USA

Full list of author information is available at the end of the article
}

\section{Biomed Central}

(C) 2015 Campbell et al. Open Access This article is distributed under the terms of the Creative Commons Attribution 4.0 International License (http://creativecommons.org/licenses/by/4.0/), which permits unrestricted use, distribution, and reproduction in any medium, provided you give appropriate credit to the original author(s) and the source, provide a link to the Creative Commons license, and indicate if changes were made. The Creative Commons Public Domain Dedication waiver (http://creativecommons.org/publicdomain/zero/1.0/) applies to the data made available in this article, unless otherwise stated. 


\section{Background}

Natural killer (NK) cells are large granular lymphocytes that participate in the innate immune response to virally infected and malignant cells. NK cells possess a diverse repertoire of natural killer cell receptors (NKRs) that allow NK cells to recognize $\mathrm{MHC}^{\text {low }}$ or $\mathrm{MHC}^{\text {negative }}$ target cells or non-classical MHC molecules (e.g. MICA/B and ULBP). The physiological functions of NK cells are regulated by a delicate balance of signals transmitted via activating and inhibitory NKRs [1]. NK cells interact with antibody $(\mathrm{Ab})$-coated target cells via the FcyRIIIa or CD16, an activating, low-affinity receptor for the Fc portion of IgG [2]. Further, our group has demonstrated in vitro and in vivo that co-stimulation of NK cells with stimulatory cytokines such as interleukin (IL)-12 significantly enhances the immune response to Ab-coated tumor cells [3]. NK cells are uniquely equipped to mediate such Ab-dependent effector functions because they contain abundant cytolytic granules, prominently express cellular adhesion molecules, constitutively express multiple cytokine receptors, and rapidly secrete immune modulatory cytokines following activation. These properties provide NK cells with the ability to directly lyse cellular targets as well as coordinate the developing adaptive immune response.

Human peripheral blood NK cells may be divided into two subsets based on their cell surface density of CD56 and CD16 molecules. The majority of NK cells (approximately $90 \%$ ) are phenotypically characterized as $\mathrm{CD} 56{ }^{\mathrm{dim}} \mathrm{CD} 16^{+}$, while the remaining cells are CD56 ${ }^{\text {bright }} \mathrm{CD} 16^{\text {neg }}$ [4]. The $\mathrm{CD} 56^{\text {bright }} \mathrm{CD} 16^{\text {neg }}$ NK cell population is thought to be the immediate precursor to the $\mathrm{CD} 56{ }^{\mathrm{dim}} \mathrm{CD} 16^{+}$subset and plays an important role in regulating immune responses via cytokine-mediated cross-talk with $\mathrm{T}$ cells and dendritic cells (DCs) [5-7]. In contrast, the cytotoxic $\mathrm{CD} 56^{\mathrm{dim}} \mathrm{CD} 16^{+} \mathrm{NK}$ cell subset expresses higher levels of chemokine receptors, and therefore is preferentially recruited to peripheral sites of inflammation [8]. Within inflammatory environments, encounters between $\mathrm{CD} 56{ }^{\mathrm{dim}} \mathrm{CD} 16^{+} \mathrm{NK}$ cells and target cells as well as exposure to locally secreted inflammatory cytokines promotes activation of this subset, leading to dramatically increased cytotoxic activity against target cells and abundant pro-inflammatory cytokine production equivalent to that of the CD $56^{\text {bright }} \mathrm{CD} 16^{\text {neg }}$ population [9-11]. The early recruitment and activation of CD56 ${ }^{\mathrm{dim}} \mathrm{CD} 16^{+} \mathrm{NK}$ cells to sites of inflammation raises important questions regarding the potential immune functions of these cells that extend beyond their cytotoxic capabilities. Thus, the present study has sought to elucidate the complex genomic profile of activated CD56 ${ }^{\mathrm{dim}} \mathrm{CD} 16^{+} \mathrm{NK}$ cells via a series of laboratory and bioinformatics-based approaches.
The systems-level bioinformatics-based approaches employed in this study build upon the results of our laboratory-based studies, augmented with publicly available data sets and knowledge collections. Specifically, we have applied network-based analysis methods to gene expression data derived from microarray analyses. In such analyses, individual biomolecular entities (e.g., genes, gene products, bio-chemical agents, etc.) belong to a larger system, with specific structural or functional relationships serving to "link" together the entities comprising that system. In these systems, the biomolecular entities may be referred to as "vertices" and the relationships that connect those vertices may be referred to as "edges" [12]. These relationships are identified via canonical information retrieval workflows. Such workflows are designed for inspection of multiple sources of relevant data; including but not limited to biomedical literature, public data sets, and collections of knowledge structured in formalized constructs known as ontologies. A simplified and illustrative example of this type of network-level systems analysis approach is provided in Fig. 1. Once a network construct is generated, it may be used to identify critical vertices that, if targeted in a diagnostic or therapeutic context, have a maximal ability to influence the function of the overall biological system in question. Indeed, it has been described that such network-based approaches may enhance the ability to identify "high yield" targets for diagnostics or therapeutics, thus optimizing the selection and pursuit of actionable and clinically relevant hypotheses [13]. To our knowledge, this is the first network analysis approach used to identify a set of high-priority gene targets based on transcriptome profiling of NK cells under unique stimulation conditions.

In this study, we present a novel application of a systems biology approach to evaluate the global patterns of gene expression in $\mathrm{CD} 56^{\mathrm{dim}} \mathrm{CD} 16^{+} \mathrm{NK}$ cells following FcR stimulation in the presence or absence of the potent immune-stimulatory cytokine, IL-12. Oligonucleotide microarrays and Real-Time PCR were utilized to elucidate expression patterns of various genes in activated NK cells. Bioinformatics-based approaches were employed to build upon our observations and inform future investigation regarding the role of activated $\mathrm{CD} 566^{\mathrm{dim}} \mathrm{CD} 16^{+} \mathrm{NK}$ cells. Further, the immunologic and bioinformatics-based analyses of NK cell function in response to clinically relevant co-stimuli presented herein may be useful for the evaluation of experimental immunologic results in future studies. Importantly, the transcriptional profiles described in this manuscript provide insight regarding the potential functions of this NK cell subset during interactions with $\mathrm{Ab}$-coated targets in the context of host defense as well as in the setting of monoclonal antibody therapy for cancer. 


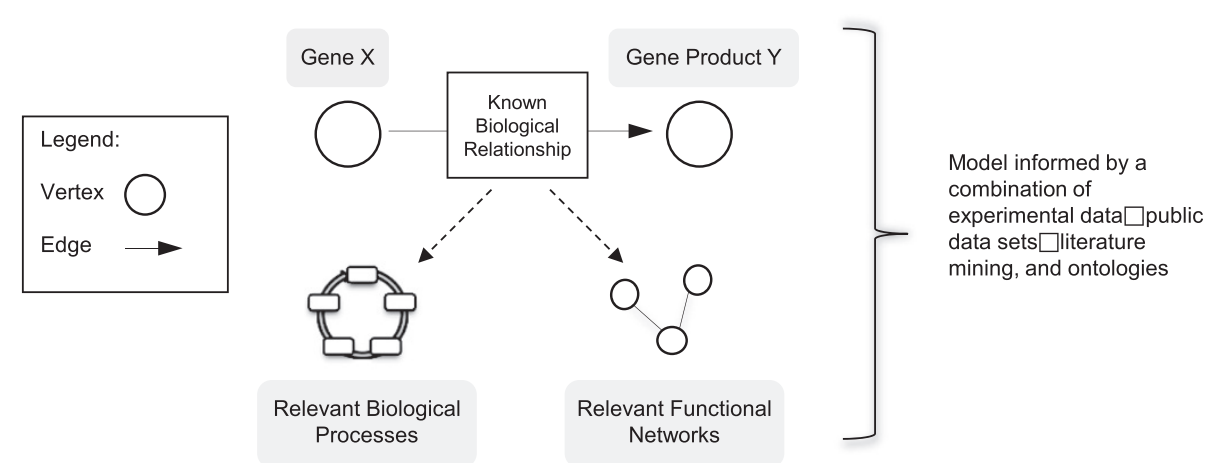

Fig. 1 Overview of the network-level systems analysis approach. This type of methodology utilizes a combination of observed data, public data sets, the mining of applicable domain literature, and/or ontologies (e.g., expertly curated collections of domain knowledge represented in a computable format). In this example, vertices (e.g., genes, gene products, and biological structures or functions) are linked together by edges that represent relevant biological relationships

\section{Methods}

\section{Cytokines and antibodies}

Recombinant human IL-12 (rhulL-12) was provided by Genetics Institute, Inc. (Cambridge, MA). Anti-FcyRIIIa antibody 3 g8 was obtained from Medarex Inc. (Annandale, NJ). Polyclonal human IgG (huIgG) was purchased from Sigma-Aldrich Co. (St. Louis, MO).

\section{Isolation of human NK cells}

NK cells were isolated directly from fresh peripheral blood Leukopaks (American Red Cross, Columbus, $\mathrm{OH}$ ) by 30-min incubation with RossetteSep cocktail (Stem Cell Technologies, Vancouver, BC), followed by ficoll hypaque density gradient centrifugation. NK cells were > $95 \% \mathrm{CD}^{2} 6^{+}$by FACS analysis. The CD $56{ }^{\mathrm{dim}} \mathrm{CD} 16^{+}$human NK cell population was isolated via FACS sorting (BD FACSAria IIu) of cells stained with CD56-PE (Beckman Coulter, Pasadena, CA) and CD16-FITC, Clone VEP13 (Miltenyi Biotec, Bergisch Gladbach, Germany) antibodies, yielding a population that was $>98 \%$ pure. Human NK cells were cultured in RPMI-1640 medium supplemented with $10 \%$ heat-inactivated pooled human $A B$ serum (HAB) (C-six Diagnostics; Germantown, WI), 100 units $/ \mathrm{mL}$ of penicillin, $100 \mu \mathrm{g} / \mathrm{mL}$ of streptomycin, and $0.25 \mu \mathrm{g} / \mathrm{mL}$ of amphotericin B (10\% HAB medium).

\section{In vitro co-stimulation assays}

For NK cell FcR activation by immobilized IgG, wells of a 96-well flat-bottom plate were coated with $100 \mu \mathrm{g} / \mathrm{mL}$ of polyclonal huIgG in cold PBS overnight at $4{ }^{\circ} \mathrm{C}$. Plates then were washed, and human NK cells were plated at 2 x $10^{5}$ cells/well with IL-12, as previously described [9]. For NK cell FcR activation by FcyRIIIa clustering, human NK cell FcyRIIIa were cross-linked with $F\left(a b^{\prime}\right)_{2}$ fragments of monoclonal $\mathrm{Ab}(\mathrm{mAb}) 3 \mathrm{~g} 8$ and goat
$\mathrm{F}\left(\mathrm{ab} \mathrm{b}^{\prime}\right)_{2}$ anti-mouse Ig secondary $\mathrm{Ab}$, in the presence of $10 \mathrm{ng} / \mathrm{mL}$ hulL-12. For FcR activation by NK cell coculture with Ab-coated tumor cells, wells of a 96-well flat-bottom culture plate were coated with the HER2overexpressing cell line SK-BR-3. $5 \times 10^{4}$ tumor cells were grown to confluence overnight at $37{ }^{\circ} \mathrm{C}$. The culture supernatant was aspirated the following day, wells were treated with $100 \mu \mathrm{g} / \mathrm{mL}$ trastuzumab (Herceptin ${ }^{\mathrm{mm}}$, an anti-HER2 $\mathrm{mAb}$ ) for $1 \mathrm{~h}$ at $37^{\circ} \mathrm{C}$ and then washed twice with warm medium to remove any unbound $\mathrm{Ab}$. Purified NK cells were added at $2 \times 10^{5}$ cells/well in the presence of $10 \mathrm{ng} / \mathrm{mL}$ rhulL-12, as previously described [9]. Control wells contained tumor plus NK cells supplemented with medium alone, trastuzumab alone, or rhulL-12 alone. Following activation, cell-free culture supernatants were harvested at the indicated time-points and analyzed for levels of human cytokines (IFN- $\gamma$, TNF$\alpha$, and MIP1- $\alpha$ ) by ELISA (Endogen, Inc, Rockford, IL). Statistical analysis of ELISA cytokine levels was performed using the Student's paired $t$-test, with $p<0.05$ considered significant.

\section{Preparation of labeled RNA and microarray hybridization}

Total cellular RNA from NK cells obtained from individual donors $(n=8)$ was isolated and subjected to a cleanup protocol with RNeasy mini kits (Qiagen, Valencia, CA), according to the manufacturer's specifications. The quality of total RNA was assessed using an Agilent Bioanalyzer. First and second strand cDNA was prepared from $8 \mu \mathrm{g}$ of total RNA, and the cDNA was subjected to in vitro transcription in the presence of biotinylated nucleoside triphosphates. The biotinylated cRNA was fragmented to uniform sizes and the integrity of the labeled cRNA was verified by gel electrophoresis. Affymetrix GeneChip expression array U133A was hybridized with each prepared 
cRNA target in duplicate, according to the manufacturer's instructions. The raw and processed microarray data is made publicly available in GEO (GSE63038).

\section{Gene microarray data analysis}

The DNA-Chip Analyzer (dChip) software package implementing model-based expression analysis of oligonucleotide arrays was used to obtain gene expression estimates for the samples in the study. The scanned microarray images were normalized using the invariant set scaling method at the probe level, and then modelbased gene expression estimates using the Perfect Match (PM) Only Model were obtained using dChip software. When examining the reproducibility of normalized duplicates for each of the eight NK donors, significant correlation was observed between each donor duplicate (average $r^{2}>0.992$, not shown).

The study was performed using a " 2 x 2 factorial" complete block design with two factors, at two levels, to understand the effect of each single simulation as well as the combined simulation, considering blocking factors as "subjects" [14]. All eight subjects were treated with four treatment combinations; no stimulation (medium), FcR stimulation by immobilized IgG, IL-12 stimulation, and combined stimulation via FcR plus IL-12. An analysis of variance test was performed for the block-treatment model with the assumption that there was no interaction between blocks and treatments for each gene. Then, pairs of treatment combinations were compared by using cell mean comparison contrasts. Since six treatment comparison contrasts were performed for each gene, Bonferroni correction was applied to correct for multiple comparisons. In each comparison, gene expression values were considered to be significantly different between two treatment combinations if the p-value $<0.008$, the median of fold changes of eight subjects was greater than 2 and the median of absolute differences in gene intensity of eight subjects was greater than 150 . Hierarchical clustering analysis was performed using the heatmap. 2 function as part of the "gplots" R package [15, 16].

Three paired comparisons were made between genes regulated in NK cells following each activation condition: 1) FcR activation by immobilized IgG vs. no stimulation (medium), 2) IL-12 vs. medium, and 3) FcR activation in the presence of IL- 12 vs. medium. Venn diagrams were constructed by intersecting the set of genes up- or down-regulated by 2 -fold or greater in each of the three comparisons. These diagrams were evaluated by Subject Matter Experts (SMEs) to assess the relative importance and/or impact of such up- or down-regulated genes in intersecting sets. Functional annotation (Gene Ontology) was performed for the up-regulated and downregulated genes in each of the three comparisons using
Database for Annotation, Visualization and Integrated Discovery (DAVID) software [17].

\section{Real-time PCR}

The expression values of select genes identified via the microarray experiments were validated by Real-Time PCR. Following RNeasy purification of NK cell lysates from the immobilized IgG assay, $2 \mu \mathrm{g}$ of total RNA was reverse transcribed and the resulting CDNA was used as a template to measure gene expression by Real-Time PCR using pre-designed primer/probe sets (Assays On Demand; Applied Biosystems, Foster City, CA) according to the manufacturer's recommendations, as previously described [18]. Human $\beta$-actin (Applied Biosystems) was used as the internal control in each reaction well. Real-Time PCR data was analyzed using the ABI PRISM 7900 Sequence Detection System.

\section{Network driven functional enrichment analysis Generating an integrated network consisting of an enriched set of functionally significant genes}

An integrated network of biomolecular features aggregated from pathway knowledge bases was created to form inductive hypotheses regarding the contribution of each differentially expressed gene in this NK cell activation study [19]. We focused our analysis on three sets of genes that were found to exhibit two-fold or greater differential expression $(p<0.008)$ when NK cells were activated in the presence of only immobilized IgG (FcR stimulus), only IL12 (IL-12R stimulus), or both IgG and IL-12. The most common biomolecular functions identified amongst the enriched set of genes were then used as filtering criteria to aggregate additional genes with the same or similar cellular, molecular, or biological functionality. This measurement of functional enrichment indicates the proportion of genes demonstrating a specific biological function within a broader collection of genes, and serves as the basis of functional enrichment analysis workflows [20]. The resulting enriched gene sets were used to prioritize genes that are influenced upon by NK-cell activation in the presence of IL-12 and immobilized IgG. The free and open-source gene function prediction service, GeneMANIA [21], was used along with the widely used large-scale network visualization and integration tool, Cytoscape [22] to formulate and visualize the resultant integrated gene network.

\section{Using Network-centric Measures to Identify Top Genes Within the Integrated Network}

Once the enriched, integrated network was constructed, the next step was to identify genes that may not have been recovered by differential gene expression analysis, but might in fact be biologically interesting by virtue of functional relationships between top genes in the integrated 
network, regardless of whether they were identified experimentally or via computational methods. One primary criterion used for the identification of the aforementioned genes was a high degree of Betweenness Centrality (BC) relative to the rest of the integrated network [23]. $\mathrm{BC}$ is quantified for a particular vertex as the number of shortest paths between pairs of other vertices in the network that pass through this vertex [24]. PAJEK, a software package for manipulation and analysis of large-scale networks, was used to calculate the BC scores [25]. Additionally, the Hyperlink-Induced Topic Search (HITS) algorithm [26] was used to measure two important characteristics of an overall genomic network, including directed linkages, namely: 1) the authority of individual genes, and 2) the hub value of individual genes. A hub vertex is quantified via summing the authority vertices that it is directed to, and an authority vertex is quantified via summing the hub vertices that are directed towards it. The HITS algorithm searches for dense links between sets of highly ranked hubs pointing to sets of highly ranked authorities.

\section{Discovering the highest represented signaling pathways with the ingenuity pathway analysis toolkit}

To complement the purely structural analysis of gene function networks, we subsequently conducted biological pathway analysis. In order to determine the top pathways represented among the genes in the integrated network described previously, the pathway analysis and visualization toolkit, Ingenuity Pathway Analysis (IPA), was used. IPA scores networks in a manner that probabilistically demonstrates that genes in the supplied data set are functionally relevant to their constituent networks. The toolkit identified several pathways that were highly relevant to the supplied gene set. The top two canonical pathways, as reported by IPA, were selected for further inspection.

\section{Results}

\section{IL-12 enhances NK cell activation in response to} immobilized IgG

The aim of this study was to determine the gene expression profile of human $\mathrm{CD} 56^{\mathrm{dim}} \mathrm{CD} 16^{+} \mathrm{NK}$ cells following FcR activation in a pro-inflammatory environment, such as that which would occur in the presence of a cytokine like IL-12 (formerly known as NK cell stimulatory factor). Previous studies examining NK cell FcR activation have utilized NK cells cultured with low-dose IL-2 or irradiated feeder cells for maintenance of NK cell viability [27-29]. In order to ensure that the gene expression data in this study were derived from an NK cell population that had been activated through the FcR alone, we utilized an immobilized IgG assay previously established in our laboratory [9]. We have demonstrated that IL-12 signal transduction enhances the NK cell cytokine response to
FcR activation in vitro, in murine models, and in phase I clinical trials [30-32]. Importantly, previous work also has shown that IL-12 is superior to IL-2, IL-15, IL-18, and IL21 in triggering cytokine secretion by FcR-stimulated NK cells [33]. We therefore examined NK cell cytokine production in response to immobilized IgG in the presence or absence of IL-12 as a means of confirming the effectiveness of this stimulation strategy. Purified NK cells that were cultured for $72 \mathrm{~h}$ in the presence of immobilized IgG and IL-12 produced large amounts of interferon-gamma (IFN- $\gamma$ ), while NK cells stimulated with immobilized IgG alone or IL-12 alone produced only moderate amounts of IFN- $\gamma$. This pattern of cytokine production was similar to that produced following NK cell activation by direct FcR cross-linking or by co-culture of NK cells with trastuzumab-coated HER2/neu positive human breast cancer cells (Fig. 2a). While maximal accumulation of IFN- $\gamma$, MIP1- $\alpha$, and TNF- $\alpha$ occurred after $72 \mathrm{~h}$ in culture, cytokine production could be detected within $6 \mathrm{~h}$ (Fig. 2b-d). Real-Time RT-PCR revealed a 20-fold increase in cytokine transcript within NK cells costimulated with immobilized IgG and IL-12 after $8 \mathrm{~h}$ in culture, with optimal transcript induction occurring at $12 \mathrm{~h}$ (Fig. 2e). These data confirmed that immobilized IgG represents a physiologically-relevant NK cell stimulus and indicated that this model would be adequate for assessment of global gene expression in a primary human $\mathrm{CD} 56^{\mathrm{dim}} \mathrm{CD} 16^{+} \mathrm{NK}$ cell population following FcR activation in the presence or absence of IL-12.

\section{Microarray analysis of NK cells stimulated via the FCR in the presence of IL-12}

In order to begin to investigate the gene expression profiles of human $\mathrm{CD} 56^{\mathrm{dim}} \mathrm{CD} 16^{+}$NK cells following co-stimulation via engagement of the FCR and IL-12R, $\mathrm{CD} 56{ }^{\mathrm{dim}} \mathrm{CD} 16^{+} \mathrm{NK}$ cells derived from eight healthy donors were purified and sorted by flow cytometry, plated separately in the four conditions of the immobilized IgG assay (medium, immobilized IgG, IL-12, or IgG plus IL-12) for $12 \mathrm{~h}$, then harvested for RNA preparation. cRNA samples from each donor were prepared. Gene expression profiling was performed by individually hybridizing the cRNA samples to the Affymetrix GeneChip expression array U133A, which interrogates 14,500 human genes.

A list of differentially expressed genes among the four stimulation conditions was compiled. Initially, four sets of gene expression intensity values were generated for each NK cell donor: resting NK cells (medium), immobilized IgG-stimulated NK cells, IL-12-stimulated NK cells, and IgG plus IL-12 co-stimulated NK cells, and next, bioinformatics analyses were performed to examine the most highly represented structural and functional relationships between differentially genes (Fig. 3a). The gene expression 

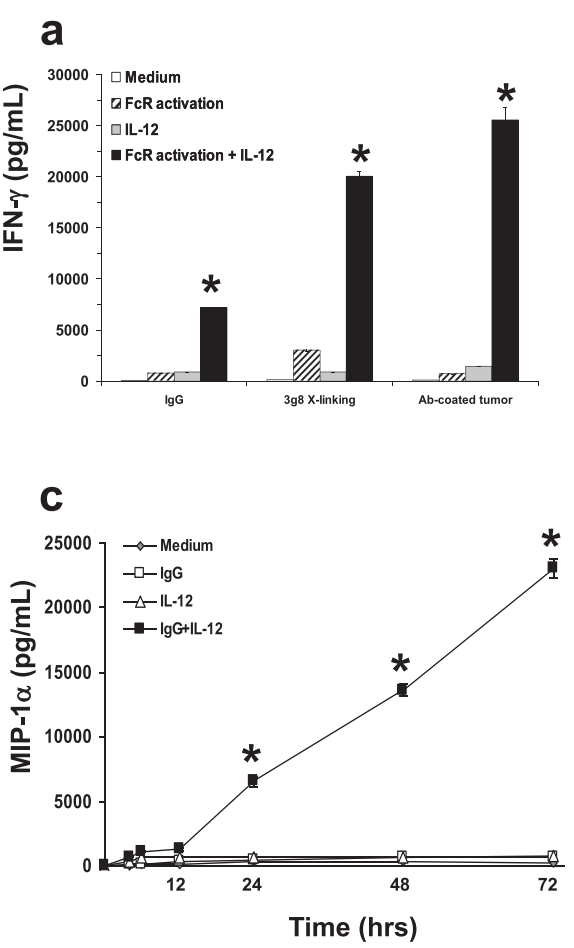

e

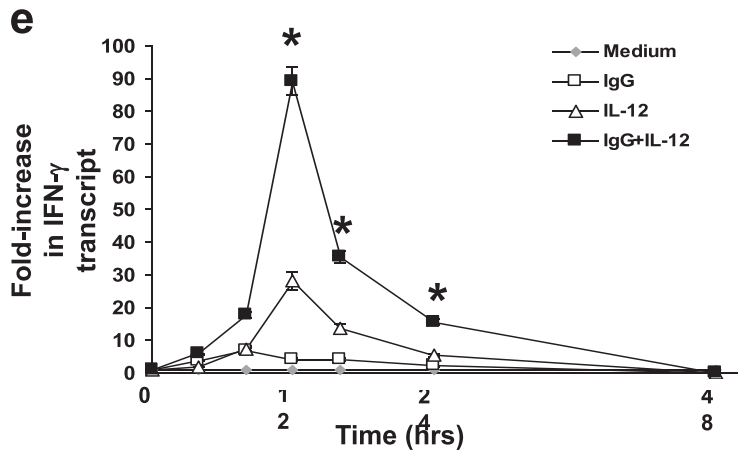

Fig. 2 NK cells secrete high levels of immune stimulatory cytokines following FcR activation in the presence of IL-12. a Human NK cells were stimulated via their FcR by culture onto wells pre-coated with either hulgG or Ab-coated SK-BR-3 tumor cells, or by direct FcR cross-linking by $3 \mathrm{~g} 8 \mathrm{Ab}$. IL-12 was added at a concentration of $10 \mathrm{ng} / \mathrm{mL}$. Control wells consisted of NK cells cultured with medium alone (medium), FcR activation alone (via immobilized hulgG, Ab-coated tumor, or $3 \mathrm{~g} 8$ cross-linking, as indicated), or IL-12 alone (IL-12). Culture supernatants were harvested after $12 \mathrm{~h}$ and analyzed for IFN- $\gamma$ content by ELISA. In time-course experiments, NK cells were cultured onto immobilized hulgG with IL-12 for varying times (4-72 h) and supernatants were analyzed for (b) IFN- $\gamma_{\text {, }}(\mathbf{c})$ MIP-1a, and (d) TNF-a. The means and SEM are shown with $n=3$ for each experiment. ${ }^{*} p<0.001$ vs. Medium, FCR activation alone, and IL-12 alone. e NK cells cultured in the immobilized IgG plus IL-12 condition were harvested at varying times and processed for Real-Time PCR analysis of IFN- $\gamma$ transcript. Results are given as fold increase in cytokine transcript over baseline (Medium). The means and SEM are shown $(n=3) .{ }^{*} p<0.01$ vs. Medium, immobilized IgG, and IL-12. Similar results were observed for gene expression of MIP-1a and TNF-a (not shown)

patterns for the four stimulation conditions were organized by a hierarchical clustering algorithm of variable genes that exhibited a 2-fold or greater change in expression. Mean levels were calculated for each gene across all samples. The magnitude of expression of a particular gene relative to the calculated mean expression was reflected by use of color representation. The resultant gene expression profiles are presented in heatmap format with corresponding dendrograms for samples and genes (Fig. 3b). The organization and length of the branches in the dendrogram reflect the similarity in gene expression profiles between each of the NK cell stimulation conditions. The distance between the branch lengths (on the horizontal axis) reflects the comparative difference in gene expression profiles between each sample. Hierarchical clustering across all samples using differentially expressed genes across any of the three comparisons showed that the four main sub-groups were correctly 


\section{a}

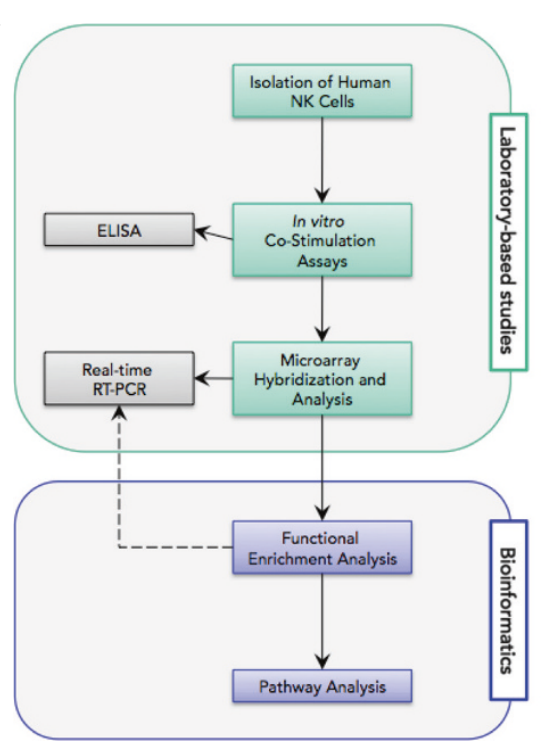

C

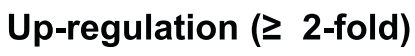

IgG+IL-12 vs. Medium

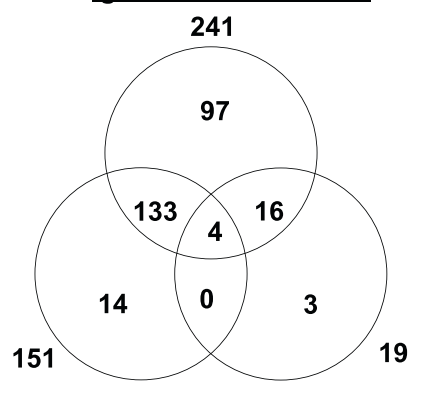

IgG vs. Medium

$\underline{\text { IL-12 vs. Medium }}$ b

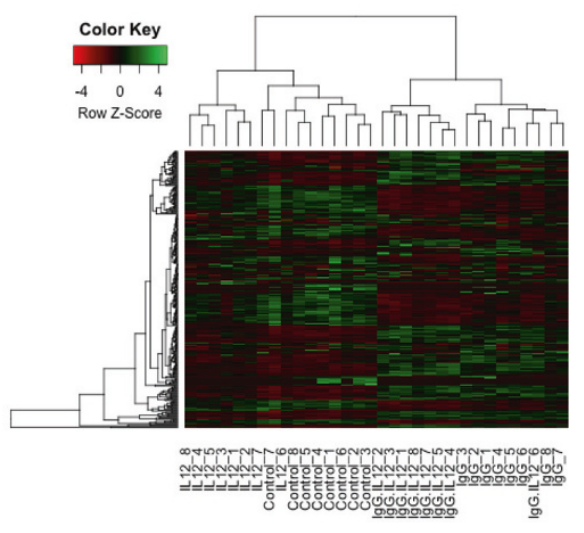

d

Down-regulation ( $\geq 2$-fold)

IgG+IL-12 vs. Medium

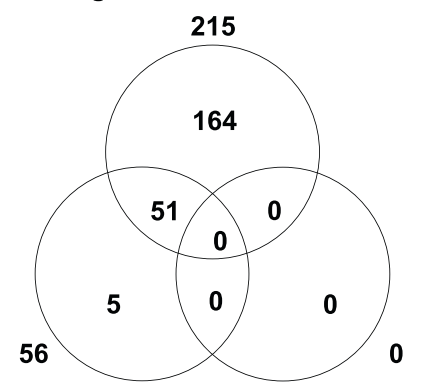

IgG vs. Medium

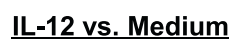

Fig. $3 \mathrm{FCR}$ activation in the presence of IL-12 results in differential expression of a unique subset of genes. a Human NK cells were isolated from peripheral blood and cultured with immobilized IgG, IL-12, or lgG and IL-12. Following stimulation, culture supernatants were harvested and levels of cytokines were analyzed by ELISA. Genomewide expression profiling was performed for NK cells derived from all 8 samples via microarray, and representative transcript expression levels were validated using Real-time RT-PCR. The bioinformatics portion of this study utilized a set of genes that exhibited the greatest expression level differences as reported by microarray. Functional enrichment analysis generated an integrated network of structural interactions among differentially expressed genes. Canonical pathway interactions were mapped using IPA. Select genes within top enriched GO functional categories were validated using Real-time RT-PCR (dotted line). $\mathbf{b}$ Hierarchical clustering based on the expression profile of genes that were up- or down-regulated by at least 2 -fold across all samples. Each row represents relative hybridization intensities of a particular gene across different samples. Colors reflect the magnitude of relative expression of a particular gene across samples. Brighter green corresponds to higher expression and brighter red corresponds to lower expression. The organization and length of the branches in the resulting dendrogram reflect the similarity in gene expression profiles between each of the samples. The division and length of the branches within the dendrogram reflect the relative similarity in gene expression profiles between each NK cell stimulation condition. The terminal branches that are close spatially in the dendrogram represent the NK cell conditions that have the most similar gene expression patterns. Venn diagrams generated by the intersection of the list of genes (c) up-regulated or (d) down-regulated by at least 2-fold vs. stimulation with medium alone are shown

classified into the corresponding four NK cell stimulation conditions with only 3 misclassifications (IL-12 sample 7, IL-12 sample 6 and IgG-IL-12 sample 6). Importantly, NK cells stimulated via the FcR (in the presence or absence of IL-12) exhibited gene expression patterns that were significantly different from that observed following stimulation with media or IL-12 alone. These initial observations suggested that the gene expression profile of immobilized
IgG plus IL-12 stimulated NK cells was distinct from that of single-condition stimulated cells and provided the rationale to further investigate the expression profile of co-stimulated NK cells.

In order to confirm the quality of these experimental results, these data were evaluated and correlated with existing gene expression data from the literature. The gene expression levels of bonafide NK cell activation 
markers were found to be up-regulated upon costimulation of NK cells via immobilized IgG and IL-12. For example, as seen in previous reports, gene expression levels of IFN- $\gamma$ and granzyme B were found to be upregulated in response to FCR and IL-12R co-stimulation. $[29,34]$. Several other genes that were up-regulated upon activation include $C K S 2, C C N D 2, C X C L 10$, and $I L-4 R$ $[29,35]$. The NK cell receptors $2 B 4$ and KLRF1 were down-regulated when NK cells were co-stimulated via immobilized IgG and IL-12, which also is consistent with previously published reports [36, 37]. (See Additional file 1 for the full list of differentially regulated genes.)

Analysis of gene expression data was initiated by performing the following comparisons: 1) immobilized IgG stimulated NK cells vs. unstimulated NK cells (medium), 2) IL-12 stimulated NK cells vs. medium, and 3) IgG plus IL-12 co-stimulated NK cells vs. medium. Genes that were differentially expressed 2-fold or greater under the stimulation conditions were included in the comparisons. Additional file 1 lists genes and their change in expression calculated from these three comparisons. The total number of genes up- or down-regulated by each stimulation condition were arranged into Venn diagrams in order to globally assess those genes that were modulated across multiple stimulation conditions and those genes that were uniquely up- or down-regulated by a specific stimulus (Fig. 3c-d). The gene expression profile of immobilized IgG-stimulated NK cells revealed that there were 151 genes that were significantly up-regulated by $>2$-fold ( 14 of those genes were up-regulated uniquely by this stimulus), while only 56 genes were down-regulated $>2$-fold ( 5 down-regulated uniquely). IL-12 stimulation led to a substantial up-regulation of 19 genes ( 3 unique to this stimulus) while no genes were significantly down-regulated. IFNG (also referred to as IFN- $\gamma$ ) was found to be upregulated 10-fold, which is consistent with previous reports describing IL-12 mediated NK cell activation [38]. Finally, 241 genes were up-regulated in response to immobilized IgG plus IL-12 co-stimulation (97 uniquely), and 215 genes were down-regulated (164 uniquely). Of note, only 4 up-regulated genes overlapped among the three comparison groups, while the majority of up-regulated genes, $133 / 151$ and $16 / 19$, uniquely overlapped between IgG and IgG + IL-12 and IL-12 and IgG + IL-12, respectively. Similarly, the majority of down-regulated genes in the IgG stimulation condition (51/56) was also recovered in the IgG + IL-12 condition. Taken together, these data suggest that NK cells co-stimulated via the FcR and IL$12 \mathrm{R}$ express a genetic profile that is unique, synergistic, and non-additive.

\section{Gene ontology classification of microarray data}

Next, up-regulated and down-regulated genes were categorized based on their functional characteristics from available gene ontology (GO) annotations in public databases (Additional file 2a-b). Additional file 3 contains a complete list of the individual genes within each functional category. Genes that were significantly upregulated in response to immobilized IgG and the combination of IgG plus IL-12 revealed that the following functional categories were over-represented in this list of genes relative to all annotated genes on the array: response to biotic stimuli, chemotaxis, NK cell mediated cytotoxicity, and promoters of apoptosis. The only GO term significantly represented by the IL-12 condition was JAK-STAT signaling, which is the predominant cytokine-associated cell-signaling pathway [39]. Similarly, statistical analyses of the genes that were down-regulated showed that the following functional categories were overrepresented in IgG plus IL-12 NK cells: cell membranelinked signal transduction, cell adhesion, response to biotic stimuli, cell cycle control, phosphorylation, and apoptosis.

\section{Genes uniquely regulated in NK cells following FcR activation in the presence of IL-12}

Given that the dual stimulation condition might best represent how NK cells respond upon encountering antibody-coated targets within an inflammatory environment, we subsequently examined those genes that were uniquely regulated by FcR activation in the presence of IL-12. The expression profile of the 97 uniquely up-regulated and 164 uniquely down-regulated genes in co-stimulated NK cells was analyzed by functional annotation of GO terms (DAVID). Functional categories and their constituent genes are depicted in Fig. 4a-e. Within the apoptosis category, genes encoding endogenous pro-apoptotic molecules such as $A S C$ (apoptosis-associated speck-like protein containing a CARD), BNIP3L (BCL2/adenovirus E1B $19 \mathrm{kDa}$ interacting protein 3-like), STK17A (serine/threonine kinase 17a apoptosis inducing) and CIDEB (cell death-inducing DFFA-like effector b) were all negatively regulated. This suggests enhanced prosurvival signaling within the co-stimulated NK cells as compared to those cells activated by a single stimulus. Also, consistent with the known cytotoxic capabilities of activated $\mathrm{CD} 56{ }^{\mathrm{dim}} \mathrm{CD} 16^{+} \mathrm{NK}$ cells, our analysis revealed several genes encoding secreted or cell-surface cytolytic molecules in the apoptosis grouping that were uniquely up-regulated in co-stimulated NK cells; e.g., granzyme B, cytochrome $c$, and multiple TNF superfamily ligands (Fig. 4a). In the cytokines and growth factors category, CXCR4 (chemokine [C-X-C motif] receptor 4), IL10RA (interleukin 10 receptor alpha), CX3CR1 (chemokine [CX3-C motif] receptor 1) and IL11RA (interleukin 11 receptor alpha) were down-regulated 3-5 fold (Fig. 4b). In the same category, three inhibitory NK cell receptors (NKRs): CD244 (natural killer receptor 2B4), CD300a, and 
a

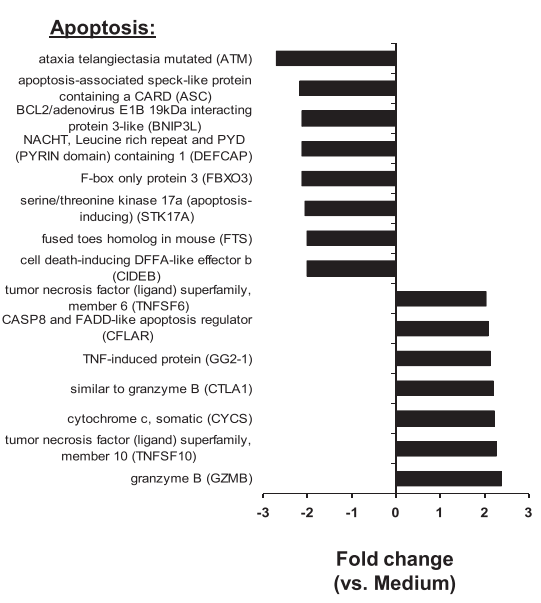

C

Cell surface signal transduction/cell adhesion:

spectrin, beta, non-ersthrocyic 1 (SPTBN1)

leukocye membrane antigen (CMRF-35H)

cell adhesion molecule 1 (CADM1)

integral membrane protein 2A(TM2A) purinergic receptor P2Y, G-protein coupled, 10
(P2RY10)

Iymphoid-restricted membrane protein (LRMP)

integrin, alpha $L$, antigen CD11A (ITGAL)

integrin, alpha 4 (antigen CD49D, alpha 4 low density lipoprotein receptor (familial
hypercholesterolemia) (LDLR)

bystin-like (BYSL)

CD38 antigen (CD38)

neuropilin (NRP) and tolloid (TLL)-like 2
(NETO2)

regulator of G-protein signalling 16 (RGS16)

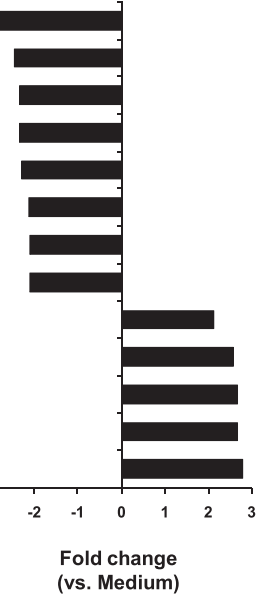

e

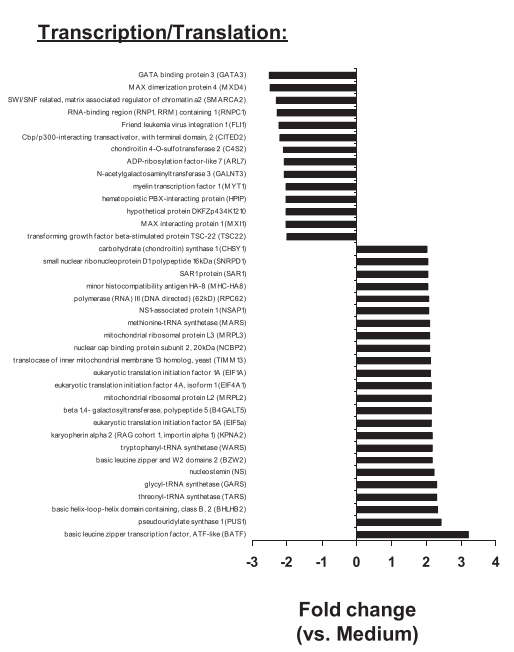

b

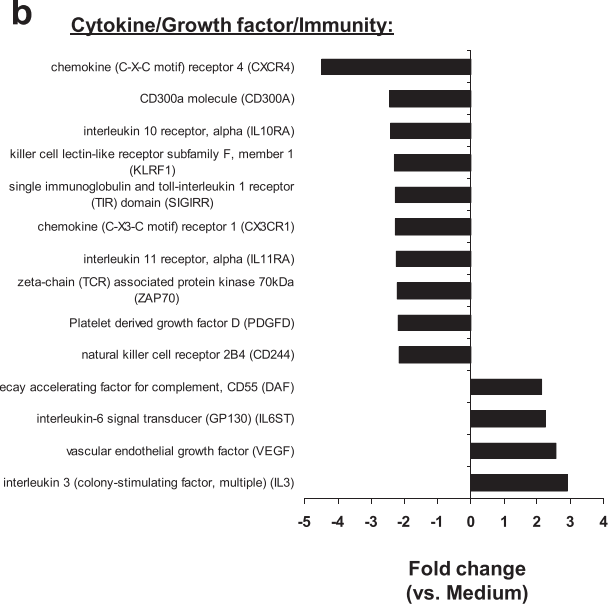

d

Cell cycle/DNA replication:

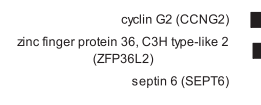

patched homolog, Drosophila (PTCH)

MLL septin-like fusion (MSF)

(RalGDS/AF-6) domain family

1(RASSF1)
DISABLED HOMOLOG 2, MITOGEN-

RESPONSIVE PHOSPHOPROTEIN

RAN, member RAS oncogene family (RAN)

TIR domain containing adaptor inducing

interferon-beta (TRIF)

ary hydrocarbon receptor (AHR)

growth arrest and DNAdamage-inducible,

alpha (GADD25A)
netastatic cells 2, protein (NM23B)

expressed in (NME2)
(NMJ)

subunit 50 okDa (POLD2)
CDC28 protein kinase regulatory subunit 2

(CKS2)

cyclin D2 (CCND2)

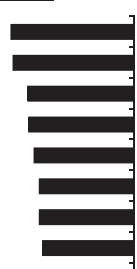

Fold change
(vs. Medium)

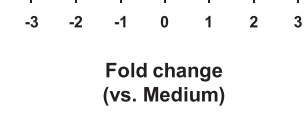

f

(vs. Medium)
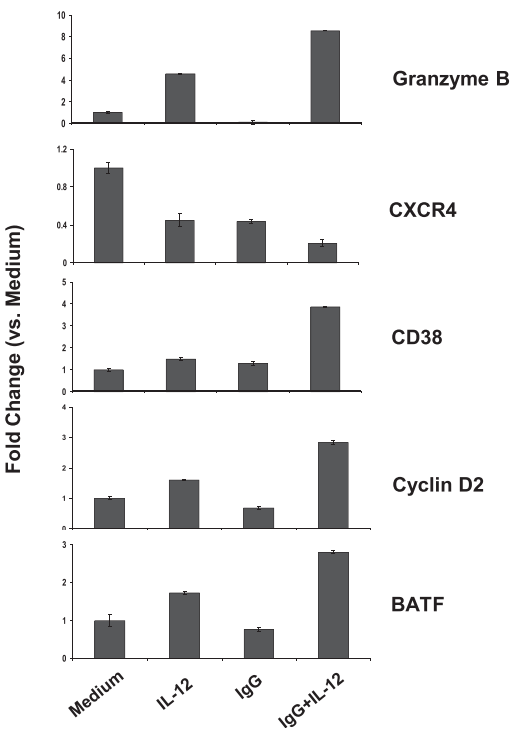

Fig. 4 (See legend on next page.) 
(See figure on previous page.)

Fig. 4 Genes uniquely regulated in NK cells following FcR activation in the presence of IL-12 grouped by function. Gene expression values of genes differentially expressed by at least 2-fold by NK cells stimulated by immobilized IgG plus IL-12 vs. those stimulated by Medium. Bars represent fold change of the mRNA level of a particular gene when comparing the subpopulations. Positive values indicate that the transcript was more abundant in the stimulated cells and negative values indicate that the gene was down-regulated in the stimulated cells. Genes were grouped according to their presumed function (a-e) based on information available in public databases or in the literature (see Materials and Methods). $\mathbf{f}$ Validation of microarray gene expression estimates by Real-Time PCR. Shown is fold change in gene expression (vs. no stimulation) within NK cells following FcR activation (lgG), IL-12 stimulation (IL-12), or FcR activation in the presence of IL-12 (IgG plus IL-12). Representative data from a single donor out of three examined is shown for each gene listed on the right

KLRF1 (killer cell lectin-like receptor subfamily F, member 1) were all uniquely down-regulated, confirming the activated state of the stimulated NK cells. The cytokine $I L-3$ was uniquely up-regulated, which may suggest a unique mechanism by which activated NK cells promote the development and proliferation of other hematopoietic cells. The cell surface signal transduction and cell adhesion molecules CADM1 (cell adhesion molecule 1), SPTBN1 (spectrin, beta, non-erythrocytic 1), ITM2A (integral membrane protein $2 \mathrm{~A}$ ) and $P 2 R Y 10$ (purinergic receptor P2Y, G-protein coupled, 10) were uniquely downregulated, and CD38 and RGS16 (regulator of G-protein signaling 16) were uniquely up-regulated (Fig. 4c). In the category cell cycle and DNA replication, uniquely downregulated genes included CCNG2 (cyclin G2), ZFP36L2 (zinc finger protein 36, C3H type-like 2), SEPT6 (septin 6). In the same category CCND2 (cyclin D2), CKS2 (CDC28 protein kinase regulatory subunit 2) were uniquely upregulated (Fig. 4d). Fig. 4e shows the expression profiles of select genes within the transcription and translation category. The uniquely down-regulated genes included several DNA binding proteins, e.g., GATA3 (GATA binding protein 3), CITED2 (Cbp/p300-interacting transactivator, with terminal domain, 2) and HPIP (hematopoietic PBXinteracting protein). The uniquely up-regulated genes included $B A T F$ (basic leucine zipper transcription factor) and several translation initiation factors (e.g., EIF1A, EIF4A1, and EIF5a).

Real-Time PCR verified the predicted changes in expression of representative genes in response to NK cell co-stimulation via immobilized IgG and IL-12 within enriched functional categories (Fig. 4f). Granzyme B may be released in cytoplasmic granules from cytotoxic $\mathrm{T}$ cells and NK cells to induce apoptosis of target cells, and RT-PCR confirmed that this gene is up-regulated following co-stimulation of NK cells (Figs. 4a and f). In the cytokine and growth factor category, CXCR4 downregulation was also validated by Real-Time PCR (Figs. 4b and f). CXCR4 has been reported to be expressed on NK cells and is involved in the migration of NK cells in response to CXCR4 ligand [40]. In the category cell surface signal transduction, the gene CD38 was upregulated approximately 4-fold (Figs. 4c and f). CD38 has been shown to associate with the FcR to activate signal transduction pathways, which includes calcium fluxes, tyrosine phosphorylation of ZAP70 and mitogenactivated protein kinase, and secretion of IFN- $\gamma$ and GMCSF [41, 42]. Cyclin D2, which belongs to the cell cycle/ DNA replication category, was confirmed to be upregulated 3-fold (Figs. 4d and f). In the category transcription and translation, BATF was found to be up-regulated 2.8-fold (Figs. 4e and f). In addition to Real-Time PCR analyses, we further incorporated bioinformatics-based approaches to gain insight regarding the mechanism of NK cell activation following FcR stimulation in the presence or absence of IL-12.

\section{Leveraging network-centric measures to discover novel genes}

It is recognized that significant alterations in individual gene expression may not comprehensively reflect the biological response of NK cells to FcR and IL-12R stimulation. Thus, we constructed a functionally enriched, integrated network connecting the differentially expressed genes identified in this study with other genes in the same or similar functional categories via GeneMANIA in order to: i) elucidate the biological context of gene expression changes of immobilized IgG and IL-12 stimulated NK cells and ii) identify additional key genes that might be involved in NK cell activation. A subset of this network including the most highly connected genes is shown in Additional file 4. Table 1 lists the top twenty genes in the network ranked according to their betweenness centrality $(\mathrm{BC})$ measures. $\mathrm{BC}$ is an indicator of the primary "bridges" between functionally segregated clusters within a gene network (see Methods). This specific relative ranking was selected as one of the criteria to analyze the network since gene-to-gene functional linkages were found to be mostly unidirectional. That is, if a gene influenced another gene via a given functional linkage, then the influenced gene would rarely reciprocate along the same functional linkage. The centrality of a node reveals its connectivity with other nodes, or genes, in an integrated network. Of note, the IL-21 receptor, $I L 21 R$, was found to exhibit the highest BC score in the integrated network. This indicates that the IL-21 receptor serves as a critical link between other important genes and relationships within the activated NK cell 
Table 1 List of most highly ranked genes based on Betweenness Centrality (BC) score

\begin{tabular}{|c|c|c|}
\hline Rank & Gene & Betweenness Centrality Score \\
\hline 1 & IL21R & 0.0921779 \\
\hline 2 & FASLG & 0.0612643 \\
\hline 3 & IRF4 & 0.0545417 \\
\hline 4 & STAT4 & 0.0455257 \\
\hline 5 & TNFRSF4 & 0.0438375 \\
\hline 6 & IL2RB & 0.0244015 \\
\hline 7 & CCR5 & 0.0233243 \\
\hline 8 & $\mathrm{P} 2 \mathrm{R} \times 5$ & 0.0203641 \\
\hline 9 & SLC7A5 & 0.0195173 \\
\hline 10 & BATF3 & 0.0192476 \\
\hline 11 & TNFRSF9 & 0.0188821 \\
\hline 12 & TBX21 & 0.0176988 \\
\hline 13 & IFNG & 0.0171686 \\
\hline 14 & IRF1 & 0.0171325 \\
\hline 15 & ACAP1 & 0.0170313 \\
\hline 16 & CXCR6 & 0.0149211 \\
\hline 17 & TRIB1 & 0.0146721 \\
\hline 18 & $\mathrm{EBI3}$ & 0.0141001 \\
\hline 19 & NFKB2 & 0.0134729 \\
\hline 20 & EIF4A1 & 0.0132968 \\
\hline
\end{tabular}

$\mathrm{BC}$ scores were calculated via the PAJEK algorithm (22), and are presented in decreasing order within the integrated network. A higher BC score indicates that a given gene is highly interconnected with other genes and gene products

gene network. Importantly, 6 out of the 20 highly ranked BC genes (CCR5, CXCR6, IL2RB, IRF1, STAT4 and $T B X 21)$ were not recovered in our filtering criteria to identify differentially expressed genes in the original microarray experiments and were exclusively identified via mapping functional linkages as described in the Methods section.

In order to illustrate a deeper level of network connectivity analysis beyond betweenness centrality, including connection cardinality, we further analyzed genes in the network according to authority and hub metrics. Table 2a classifies the highest ranked genes according to their authority measures $(n=9)$, while Table $2 \mathrm{~b}$ includes a set of genes ranked according to their hub measures $(n=9)$. Using the HITS algorithm, a node achieves a high authority measure when several important nodes within the integrated network point to it. In this study, a high authority measure indicates a gene that is a suitable indicator of the functional patterns in its neighborhood within the gene network. In contrast, a high hub measure is an indicator of the direct connections a node makes with other nodes in the integrated network. If a node with a high hub measure is removed from the
Table $\mathbf{2}$ List of most highly ranked genes based on Authority or Hub scores

\begin{tabular}{ll}
\hline A & \\
Rank & Authorities \\
1 & NLRP1 \\
2 & BIRC3 \\
3 & EIF4A1 \\
4 & FAS \\
5 & CFLAR \\
6 & TNFRSF9 \\
7 & PTPRCAP \\
8 & EGR3 \\
9 & IFNG \\
B & \\
Rank & Hubs \\
1 & CASP1 \\
2 & FASLG \\
3 & TRAF1 \\
4 & NFKB1 \\
5 & NFKBIA \\
6 & TNFRSF1B \\
7 & FAS \\
8 & IL11RA \\
9 & PTPRC \\
\hline The HITS algorithm was used to measure two important characteristics of an \\
overall genomic network: the authority of individual genes, which may be \\
interpreted as a surrogate marker for the relative "importance" of those genes \\
to the overall function of the network (Table 2a); and the hub value of \\
individual genes, which is a surrogate marker for the relative "impact" of that \\
gene on the interconnections or relationships between genes that make up \\
that same network (Table 2b). Authority and Hub scores are presented in \\
decreasing order within the integrated network \\
\hline
\end{tabular}

network, the entire network will be disrupted, and previously connected sub-networks will fragment into unconnected gene clusters. In order to obtain numerical scores, authority nodes are quantified via summing the hub nodes that are directed towards them, and hub nodes are quantified via summing the authority nodes that it are directed towards them. NLRP1 was the highest ranked authority gene, followed by $B I R C 3$ and EIF4A1. In regards to important hub genes, CASP1 was found to be the most important followed by FASLG and TRAF1. Of note, all of the authority genes were identified in the original microarray differential expression analyses. Interestingly, nearly $45 \%$ (4 out of 9) hub genes were exclusively recovered via computational means and mapping functional linkages. These four genes include NFKBIA, PTPRC, TNFRSF1B and the topranked hub gene, $C A S P 1$. Further, no individual gene was identified as a combined highly ranked $\mathrm{BC}$, authority, and hub gene. Only 1 out of the 9 hub and 9 authority genes 
was found to be common between the two groups: namely FAS. Similarly, only FASLG was identified as both a hub and $\mathrm{BC}$ gene. A slightly higher proportion of authority genes (3/9) were found to be $\mathrm{BC}$ genes, and vice versa (3/ 20 BC genes): EIF4A1, TNFRSF9, and IFNG.

\section{Discovering the highest represented pathways}

We next used Ingenuity Pathway Analysis (IPA) to illustrate the most common canonical pathways associated with the genes that were differentially expressed (2-fold or greater regulation) in NK cells stimulated by immobilized IgG plus IL-12 as well as those contained in the enriched integrated network for this stimulation condition. The top two IPA pathway networks are shown in Fig. 5. The top two networks were chosen so that the resultant integrated network was not too dense to be visualized as a twodimensional image. Table 3 lists constituent genes of the top two pathways, where the differentially expressed genes identified in the original microarray analysis are highly represented. Future functional studies of the key genes regulating NK cell signaling pathways identified in these analyses may unveil previously unknown drivers of NK cell function in the setting of monoclonal antibody therapy for cancer.

Together, results derived from both canonical pathway and topological network analyses provide insight into the diverse, interwoven network of genes involved in NK cell activation. The systems-level observations generated in this study may serve as a basis for identification of important candidate genes to be investigated in future functional studies and subsequently, serve as targets for diagnostic or therapeutic interventions.

\section{Discussion}

The major goal of this study was to gain insight into the function of NK cells upon encounters with Ab-coated

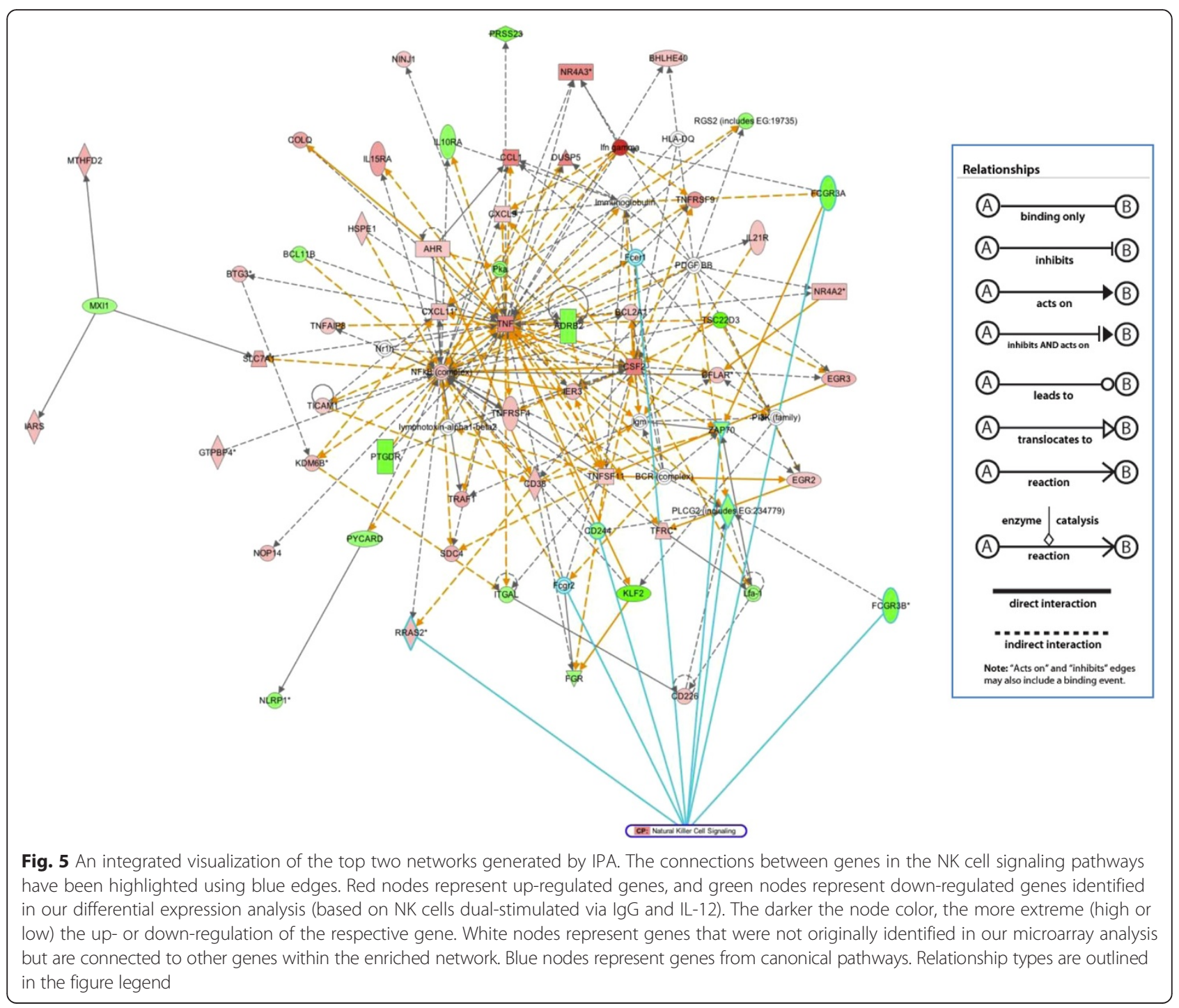


Table 3 Top two networks along with their constituent genes and associated canonical scores as calculated by IPA.

\begin{tabular}{|c|c|c|c|}
\hline ID & Molecules in the Network & $\begin{array}{l}\text { IPA } \\
\text { Score }\end{array}$ & Top Functions \\
\hline 1 & $\begin{array}{l}\text { ADRB2, BCL11B, BHLHEA40, BTG3, CD38, COLQ, CSF2, DUSP5, EGR2, EGR3, Fcgr2, } \\
\text { FCGR3A, FGR, HLA-DQ, HSPE1, IARS, IER3, Ifn gamma, IL21R, KDM68, lymphotoxin- } \\
\text { alpha1-beta2, MTHFD2, MXI1, NINJ1, Nr1h, NR4A2, NR4A3, PDGF BB, Pka, PRSS23, } \\
\text { PTGDR, RGS2 (includes EG:19735), SDC4, SLC7A1, TNF }\end{array}$ & 37 & $\begin{array}{l}\text { Connective Tissue Disorders, Immunological } \\
\text { Disease, Inflammatory Disease }\end{array}$ \\
\hline 2 & $\begin{array}{l}\text { AHR, BCL2A1, BCR (complex), CCL1, CD226, CD244, CFLAR, CXCL9, CXCL11, Fcer1, } \\
\text { FCGR3B, GTPBP4, Igm, IL10RA, IL15RA, Immunoglobulin, ITGAL, KLF2, Lfa-1, NFkB } \\
\text { (complex), NLRP1, NOP14, PI3K (family), PLCG2 (includes EG:234779), PYCARD, } \\
\text { RRAS2, TFRC, TICAM1, TNFAIP8, TNFRSF, TNFRSF9, TNFSF11, TRAF1, TSC22D3, } \\
\text { ZAP70 }\end{array}$ & 37 & $\begin{array}{l}\text { Cellular Development, Cellular Growth and } \\
\text { Proliferation, Hematological System Development } \\
\text { and Function }\end{array}$ \\
\hline
\end{tabular}

The gene names in bold text indicate those genes that were included in the original microarray data set for NK cells stimulated via IgG and IL-12. The assertion "top two" indicates that the maximal number of genes from the integrated network belonged to these two pathways according to the IPA analysis tool

targets in the presence of locally secreted cytokines from both an immunological and bioinformatics-based perspective. In the present study, we utilized oligonucleotide microarrays to evaluate the gene expression profile of NK cells following FcR activation in the presence of the powerful pro-inflammatory cytokine, IL-12. We further employed several systems-level analyses, including functional enrichment as well as network centrality and pathway analysis, in order to determine key genes and biological functions influencing the responses of $\mathrm{NK}$ cells encountering Ab-coated target cells in an inflammatory environment. The most common biomolecular functions identified amongst the differentially expressed genes were utilized to aggregate additional genes with the same or similar cellular, molecular, or biological functionality into an integrated network. Furthermore, network analysis metrics, including betweenness centrality, authority, and hub measures were employed to rank the relative importance of genes in the overall integrated network. To our knowledge, this is the first application of sophisticated network-level analyses to describe the genetic profile of a clinically relevant population of activated NK cells. We report herein the gene expression profile induced within FcR and cytokine stimulated NK cells and highlight potential key regulators of NK cell activity in inflammatory settings.

Several unique genes in the combined immobilized IgG plus IL-12 stimulation condition exhibited significance in both the microarray data set as well as the enriched gene network generated in the bioinformaticsdriven portion of this study. Select members of the Tumor Necrosis Factor Receptor Superfamily (TNFRSF) were found to be significantly up-regulated in the microarray gene expression studies and were identified as key entities in the overall enriched network (TNFRSF4: BC Rank 5, TNFRSF9: BC Rank 11 and Authority Rank 6, and TNFRSF1B: Hub Rank 6). Accordingly, TNF- $\alpha$ induction in immobilized IgG plus IL-12 activated NK cells was confirmed via enzyme-linked immunosorbent assays (ELISA) as well as RT-PCR studies. Moreover, the
Basic leucine zipper transcription factor, ATF-like (BATF, $B C$ Rank 10) was the most highly up-regulated gene in the Transcription/Translation category of the microarray studies. This gene has been shown to interact with Interferon Regulatory Factor 4 (IRF4, BC Rank 3 in the enriched network generated in this study) to promote transcriptional activation in $\mathrm{T}$ cells, support development of dendritic cells, and to aid in the immune response against invading pathogens $[43,44]$. The results in this study may indicate a potential role for $B A T F$ and IRF4 interactions in the NK cell response to immunebased therapies. Also, recent studies have examined the role of the Aryl Hydrocarbon Receptor (AHR) in NK cell development [45]. It has been suggested that AHR influences the expression of the transcription factor T-Box Protein 21 (TBX21) and has downstream effects on NK cell IFN- $\gamma$ production. In this study, IFN- $\gamma$ production was significantly increased in FCR and IL-12R activated NK cells, and this gene exhibited a BC Rank 13 and Authority Rank 9 in the enriched gene network. Moreover, $A H R$ expression was up-regulated 2-fold in the microarray data set, and TBX21 exhibited a BC Rank 12 in the enriched gene network. The importance of $A H R$, TBX21, and IFNG were highlighted in both laboratoryand bioinformatics-based portions of this study, supporting further investigation into their interactions and potential role in the function of activated NK cells. In summary, these findings indicate that genes identified using genome-wide profiling and those that were prioritized via computational functional enrichment and pathway analyses may serve as interesting targets for future studies to better understand the mechanisms underlying NK cell activation.

Interestingly, bioinformatics-based analyses revealed that the $I L 21 R$ exhibited the highest BC score within the activated NK cell gene network, indicating its importance within the genetic framework governing NK cell anti-tumor activity. In the laboratory-based studies, evaluation of $I L 21 R$ expression by Real-Time PCR revealed an intriguing differential regulation that may 
explain the mechanisms utilized by NK cells upon encounters with Ab-coated targets in different environments. For example, expression of the $I L 21 R$ was significantly enhanced in response to $\mathrm{FCR}$ activation alone, but neither enhanced nor inhibited in response to FcR activation in the presence of IL-12. Previous reports have shown that IL-21 enhances CD56 ${ }^{\mathrm{dim}} \mathrm{CD} 16^{+}$NK cell cytotoxicity and cytokine production in response to Ab-coated targets $[46,47]$. Hence, up-regulation of the IL21R upon encounters with Ab-coated targets alone may reflect an endogenous mechanism that allows for rapid enhancement of NK cell activity responsible for further inflammation and recruitment of the adaptive immune response. As a key player within the integrated gene network, additional investigation is essential in order to better understand the complex role of IL-21 and its receptor on NK cell anti-tumor activity.

Further, given that immune cell crosstalk plays a critical role in the anti-tumor immune response, we were interested in the regulation of genes that may facilitate cellular interactions between activated NK cells and other immune cells within the tumor microenvironment. In particular, myeloid-derived suppressor cells (MDSCs) increasingly have been recognized as major players in suppression of the anti-tumor immune response. While several manuscripts have highlighted the importance of interactions between $\mathrm{T}$ cells and MDSCs, less is known about the relationship between NK cells and MDSCs [48, 49]. The current study provides several interesting observations suggesting the potential for crosstalk between activated NK cells and MDSCs. Following stimulation of the FCR and IL-12R, NK cell expression of the IL-10 receptor (IL10RA) was significantly down-regulated according to the microarray and bioinformatics-based analyses. This is of interest, as several reports have shown that MDSCs produce IL-10, and IL-10 also has been shown to promote NK cell proliferation and cytotoxic activity against tumor cells [50-53]. In addition, dual stimulated NK cells exhibited increased expression of CSF2 (also known as GM-CSF) and TNF. Both of these cytokines have been demonstrated to drive the accumulation and suppressive function of MDSCs in multiple tumor models [54, 55]. TNFRSF9 was shown to be an important player in both the microarray data set and in various bioinformaticsbased analyses as well. TNFRSF9 associates with 41BB to form CD137, a T cell and NK cell co-stimulatory molecule. Signaling via CD137 has been shown to suppress $\mathrm{CD} 4^{+} \mathrm{T}$ cell activation, stimulate $\mathrm{CD} 8^{+} \mathrm{T}$ cell activity and increase proliferation of $\mathrm{CD} 1 \mathrm{~b}^{+} \mathrm{Gr}-1^{+}$myeloid derived suppressor cells (MDSCs) [56]. Notably, recent studies have demonstrated increased CD137 expression on NK cells following interactions with mAb-coated tumor cells [57]. NK cell anti-tumor activity therefore may be enhanced via combination therapy including a tumor antigen-specific mAb and an agonistic anti-CD137 mAb. In addition, it may be important to examine the impact of anti-CD137 mAb therapy on inhibitory MDSC in future studies. Lastly, we observed an increase in CCL1 expression in dual stimulated NK cells. Studies have shown that MDSCs from patients with urothelial and renal cell carcinoma express CCR8 (the CCL1 receptor), and tumorderived CCL1 promotes the accumulation of MDSCs in both the peripheral blood and tumor tissue [58]. While identifying potential interactions between NK cells and MDSCs was not the primary objective of this study, our observations suggest that further investigation to better understand NK cell and MDSC crosstalk will yield informative results regarding the immune response to monoclonal antibody therapy for cancer.

Network-based approaches have been successfully applied in a variety of immune cell contexts. In a recent study comparing the transcriptional responses of NK cells activated via $P$. falciparum laboratory strain $3 \mathrm{D} 7$ and NK cells treated with IL-12 and IL-18, the authors used microarray and networks analysis to identify distinct genes and pathways involved in these responses including TREM1 signaling and protein ubiquitination processes [59]. In another study analyzing gene expression signatures using Ingenuity database information and Bayesian inference in the context of $\mathrm{T}$ cell activation, Jagged1 was shown to modulate $\mathrm{T}$ cell activation in PBMCs from multiple sclerosis patients [60]. The authors further showed that a Jagged1 agonist ameliorated the disease course in a mouse model of autoimmune encephalomyelitis. Additional applied immunoinformatics frameworks include the statistically powerful weighted gene co-expression network analysis (WGCNA), whereby novel biological modules and pathways may be discovered [61], as well as ontology-based methods to define novel biomarkers and infer biological functions [62].

Our immunological evaluation of activated NK cells could be limited in the current study because only one type of co-stimulation condition, immobilized IgG and IL12, was examined. Of note, as shown in Fig. 3a, NK cell IFN- $\gamma$ production was greater in response to co-culture with trastuzumab-coated cells and IL-12 compared to that of immobilized IgG and IL-12 stimulated cells. This finding could indicate that a potentially different stimulatory environment may be encountered by NK cells interacting with Ab-coated tumor cells as compared to those that engage only immobilized IgG. Further, incorporating multiple NK cell stimulation strategies may more effectively represent the complex relationships among other cytokines and NK cell activity. For instance, Smith et al. performed a small-scale study of global gene expression changes in NK cells co-stimulated by IL-2, IL-12, and IL18 compared to unstimulated NK cells [63]. Like our study, the authors found that several effector cytokines, 
including IFNG as well as various TNF family members, were transcriptionally up-regulated in response to costimulation. Of the top 150 genes differentially expressed in the Smith et al. study, nearly $10 \%$ were sequencespecific DNA-binding transcription factors, which is consistent with the central role of nuclear transcription factor responses in activated NK cells demonstrated in this study. Though our in vitro validation of microarray gene expression estimates by Real-Time PCR was somewhat limited in scope, future studies will include additional functional analyses of high-yield gene targets based on this initial genome-wide investigation. Also, utilizing heuristically defined thresholds ( $>2$-fold changes in gene expression) to define significance may have limited our ability to recover genes that were more subtly expressed individually, but in combination with other genes, may represent important regulators of NK cell activation. Further interrogation of co-expression modules and integration of additional canonical knowledge and experimental evidence will advance our current findings. An important resource for future integrative genomics studies is The Immunological Genome Project (ImmGen) database of murine-derived gene expression and regulatory networks of all immune cells [64]. For example, Xue et al. conducted transcriptome and network-based analyses of human macrophage activation and subsequently integrated their data with core signatures of dendritic cells and macrophages contained within ImmGen. In doing so, they were able to classify several conserved genes involved in regulation of macrophage activation [65]. A preliminary analysis of ImmGen NK cell wholegenome microarray data sets demonstrated a unique transcriptional relationship between resting NK cells and $\mathrm{T}$ cells and may serve as a valuable resource for future studies investigating the global molecular aspects underlying NK cell function [66].

\section{Conclusions}

This study has combined bioinformatics-driven network analyses with immunological laboratory-based studies to identify important genes modulating NK cell function following physiologically relevant activation. By utilizing an integrated approach that brings together multiple networklevel analyses, we have created a compendium of important genes and pathways for future study. The results presented herein highlight the involvement of a number of genes simultaneously regulated within NK cells following cytokine and FcR activation and suggest unique mechanisms by which $\mathrm{CD} 56{ }^{\mathrm{dim}} \mathrm{CD} 16^{+}$NK cells respond to Ab-coated targets under pro-inflammatory conditions. It is our hope that this study may serve as the first step towards a powerful mechanism for evaluating genetic functionality in the context of a multi-dimensional, multi-disciplinary approach to understanding NK cell function.

\section{Availability of supporting data}

The microarray dataset may be accessed via the following Gene Expression Omnibus (GEO) link (accession number GSE63038): http://www.ncbi.nlm.nih.gov/geo/ query/acc.cgi?acc=GSE63038.

\section{Additional files}

\begin{abstract}
Additional file 1: Supplemental Table 1 provides a full list of differentially expressed (2-fold or greater) genes from the microarray studies and their change in expression calculated from the following comparisons: 1) immobilized IgG stimulated NK cells vs. unstimulated NK cells (medium), 2) IL-12 stimulated NK cells vs. medium, and 3) IgG plus IL-12 co-stimulated NK cells vs. medium. (XLS $125 \mathrm{~kb}$ )

Additional file 2: $2 \mathrm{a}$ and $\mathbf{2 b}$ are entitled Functional analysis of the genes regulated in NK cells following FcR activation, IL-12 stimulation or the combination reveals distinct functional grouping in each gene list (DAVID). These figures represent the functional characteristics of up(2a) or down-regulated (2b) genes from available gene ontology (GO) annotations in public databases. (PPT $159 \mathrm{~kb}$ )
\end{abstract}

Additional file 3: Supplemental Table 2 contains a complete list of the individual genes within each functional category. (XLS $45 \mathrm{~kb}$ )

Additional file 4: A sub-network among 33 unique genes representing the hub, authority and high $\mathrm{BC}$ ranked vertices from the overall integrated network. (PPT $407 \mathrm{~kb}$ )

\section{Abbreviations}

NK: Natural killer; ADCC: Antibody-dependent cell-mediated cytotoxicity; PBMC: Peripheral blood mononuclear cell; mAb: Monoclonal antibody; IgG: Immunoglobulin G antibody; DC: Dendritic cell; MDSC: Myeloid-derived suppressor cell; NKR: NK cell receptor; GO: Gene ontology; IPA: Ingenuity Pathway Analysis; BC: Betweenness Centrality; GSEA: Gene Set Enrichment Analysis.

\section{Competing interests}

The authors declare that they have no competing interests.

\section{Authors' contributions}

ARC, NB, RP, and SVK performed the immunology laboratory-based studies and subsequent analysis. ARC, NB, KR, AP, ARS, PT, and SDS drafted the manuscript. $\mathrm{NB}, \mathrm{RP}, \mathrm{PT}, \mathrm{RD}$ assisted with microarray study design and analysis. KR, AP, SL, OL, RD carried out bioinformatics based-studies and network analyses. PROP and WEC conceived of the study, and participated in its design and coordination, and helped to draft the manuscript. All authors read and approved the final manuscript.

\section{Acknowledgements}

The authors thank The Ohio State University Comprehensive Cancer Center (CCC) Microarray Core Facility for performing CRNA hybridization and raw data collection. We also thank The Ohio State University CCC Real-Time Core Facility for assisting in the operation of the ABI PRISM 7900 Sequence Detection System. This work was supported, in part, by the Susan G. Komen Breast Cancer Foundation Dissertation Research Award (RP) and the Pelotonia Graduate Research Fellowship (ARC). In addition, the authors acknowledge the support of NIH grants P01 CA95426 and 5T15LM011270-02.

\section{Author details}

${ }^{1}$ The Arthur G. James Comprehensive Cancer Center and Solove Research Institute, The Ohio State University, Columbus, OH 43210, USA. ${ }^{2}$ Medical Scientist Training Program and Biomedical Sciences Graduate Program, The Ohio State University, Columbus, $\mathrm{OH} 43210$, USA. ${ }^{3}$ Department of Biomedical Informatics, The Ohio State University, Columbus, OH 43210, USA.

${ }^{4}$ Department of Pediatrics, The Cleveland Clinic, Cleveland, OH 44106, USA. ${ }^{5}$ Division of Human Cancer Genetics, The Ohio State University, Columbus, $\mathrm{OH} 43210$, USA. ${ }^{6}$ Departments of Oncology and Medicine, Wayne State University and Barbara Ann Karmanos Cancer Institute, Detroit, MI 48201, 
USA. ${ }^{7}$ Robert H. Lurie Comprehensive Cancer Center, Northwestern University, Chicago, IL 60611, USA. ${ }^{8}$ Department of Surgery, The Ohio State University, Columbus, OH 43210, USA. ${ }^{9}$ The Ohio State University College of Medicine, N924 Doan Hall, 410 West 10th Ave., Columbus, OH 43210, USA.

\section{Received: 20 March 2015 Accepted: 7 October 2015} Published online: 15 October 2015

\section{References}

1. Robertson MJ, Ritz J. Biology and clinical relevance of human natural killer cells. Blood. 1990;76(12):2421-38.

2. Perussia B. Fc receptors on natural killer cells. Curr Top Microbiol Immunol. 1998;230:63-88.

3. Luedke E, Jaime-Ramirez AC, Bhave N, Roda J, Choudhary MM, Kumar B, et al. Cetuximab therapy in head and neck cancer: immune modulation with interleukin-12 and other natural killer cell-activating cytokines. Surgery. 2012;152(3):431-40.

4. Cooper MA, Fehniger TA, Turner SC, Chen KS, Ghaheri BA, Ghayur T, et al. Human natural killer cells: a unique innate immunoregulatory role for the CD56(bright) subset. Blood. 2001;97(10):3146-51.

5. Cooper MA, Fehniger TA, Fuchs A, Colonna M, Caligiuri MA. NK cell and DC interactions. Trends Immunol. 2004:25(1):47-52.

6. Kalinski P, Mailliard RB, Giermasz A, Zeh HJ, Basse P, Bartlett DL, et al. Natural killer-dendritic cell cross-talk in cancer immunotherapy. Expert Opin Biol Ther. 2005;5(10):1303-15.

7. Yu J, Mao HC, Wei M, Hughes T, Zhang J, Park IK, et al. CD94 surface density identifies a functional intermediary between the CD56bright and CD56dim human NK-cell subsets. Blood. 2010;115(2):274-81.

8. Cooper MA, Fehniger TA, Caligiuri MA. The biology of human natural killer-cell subsets. Trends Immunol. 2001:22(11):633-40.

9. Parihar R, Dierksheide J, Hu Y, Carson WE. IL-12 enhances the natural killer cell cytokine response to Ab-coated tumor cells. J Clin Invest. 2002;110(7):983-92.

10. Ferlazzo G, Pack M, Thomas D, Paludan C, Schmid D, Strowig T, et al. Distinct roles of IL-12 and IL-15 in human natural killer cell activation by dendritic cells from secondary lymphoid organs. Proc Natl Acad Sci U S A 2004;101(47):16606-11.

11. Ferlazzo G, Thomas D, Lin SL, Goodman K, Morandi B, Muller WA, et al. The abundant NK cells in human secondary lymphoid tissues require activation to express killer cell lg-like receptors and become cytolytic. J Immunol. 2004;172(3):1455-62

12. Barabási AL, Oltvai ZN. Network biology: understanding the cell's functional organization. Nat Rev Genet. 2004;5(2):101-13.

13. Barabási AL, Gulbahce N, Loscalzo J. Network medicine: a network-based approach to human disease. Nat Rev Genet. 2011:12(1):56-68.

14. Yang $\mathrm{YH}$, Speed T. Design issues for CDNA microarray experiments. Nat Rev Genet. 2002;3(8):579-88.

15. Eisen MB, Spellman PT, Brown PO, Botstein D. Cluster analysis and display of genome-wide expression patterns. Proc Natl Acad Sci U S A. 1998;95(25):14863-8.

16. Warnes GR, Bolker B, Bonebakker L, Gentleman R, Huber W, Liaw A, et al. gplots: various R programming tools for plotting data. 2012. http://CRAN R-project.org/package=gplots.

17. Dennis Jr G, Sherman BT, Hosack DA, Yang J, Gao W, Lane HC, et al. DAVID: Database for Annotation, Visualization, and Integrated Discovery. Genome Biol. 2003:4(5):3.

18. Rajeevan MS, Ranamukhaarachchi DG, Vernon SD, Unger ER. Use of real-time quantitative $P C R$ to validate the results of CDNA array and differential display PCR technologies. Methods San Diego Calif. 2001;25(4):443-51.

19. Kell DB, Oliver SG. Here is the evidence, now what is the hypothesis? The complementary roles of inductive and hypothesis-driven science in the post-genomic era. Bioessays. 2004:26(1):99-105

20. Subramanian A, Tamayo P, Mootha VK, Mukherjee S, Ebert BL, Gillette MA, et al. Gene set enrichment analysis: a knowledge-based approach for interpreting genome-wide expression profiles. Proc Natl Acad Sci U S A. 2005;102(43):15545-50.

21. Mostafavi S, Ray D, Warde-Farley D, Grouios C, Morris Q. GeneMANIA: a real-time multiple association network integration algorithm for predicting gene function. Genome Biol. 2008;9(1):S4

22. Shannon P, Markiel A, Ozier O, Baliga NS, Wang JT, Ramage D, et al. Cytoscape: a software environment for integrated models of biomolecular interaction networks. Genome Res. 2003;13(11):2498-504.
23. Towfic F, VanderPlas S, Oliver CA, Couture O, Tuggle CK, West Greenlee MH, et al. Detection of gene orthology from gene co-expression and protein interaction networks. BMC Bioinform. 2010;11(3):S7.

24. FREEMAN L. SET OF MEASURES OF CENTRALITY BASED ON BETWEENNESS Sociometry. 1977;40(1):35-41.

25. Batagelj V, Mrvar A: Pajek - Analysis and visualization of large networks Math Visual 2004:95:77-103

26. Kleinberg JM. Authoritative sources in a hyperlinked environment. J Acm. 1999;46(5):604-32.

27. London L, Perussia B, Trinchieri G. Induction of proliferation in vitro of resting human natural killer cells: IL 2 induces into cell cycle most peripheral blood NK cells, but only a minor subset of low density T cells. J Immunol. 1986;137(12):3845-54

28. Voss SD, Daley J, Ritz J, Robertson MJ. Participation of the CD94 Receptor Complex in Costimulation of Human Natural Killer Cells. J Immunol. 1998;160(4):1618-26.

29. Hanna J, Bechtel P, Zhai Y, Youssef F, McLachlan K, Mandelboim O. Novel insights on human NK cells' immunological modalities revealed by gene expression profiling. J Immunol. 2004;173(11):6547-63.

30. Parihar R, Nadella P, Lewis A, Jensen R, De Hoff C, Dierksheide JE, et al. A Phase I Study of Interleukin 12 with Trastuzumab in Patients with Human Epidermal Growth Factor Receptor-2-Overexpressing Malignancies. Clin Cancer Res. 2004;10(15):5027-37.

31. Kondadasula SV, Roda JM, Parihar R, Yu J, Lehman A, Caligiuri MA, et al. Colocalization of the $\mathrm{IL}-12$ receptor and FcgammaRIlla to natural killer cell lipid rafts leads to activation of ERK and enhanced production of interferongamma. Blood. 2008;111(8):4173-83.

32. Bekaii-Saab TS, Roda JM, Guenterberg KD, Ramaswamy B, Young DC Ferketich AK, Lamb TA, Grever MR, Shapiro CL, William E. Carson I: A Phase I Trial of Paclitaxel and Trastuzumab in Combination with Interleukin-12 in Patients with Her2/neu-Expressing Malignancies. Molecular Cancer Therapy 2009 , In press.

33. Roda JM, Joshi T, Butchar JP, McAlees JW, Lehman A, Tridandapani S, et al. The activation of natural killer cell effector functions by cetuximab-coated, epidermal growth factor receptor positive tumor cells is enhanced by cytokines. Clin Cancer Res. 2007;13(21):6419-28.

34. Koopman LA, Kopcow HD, Rybalov B, Boyson JE, Orange JS, Schatz F, et al. Human Decidual Natural Killer Cells Are a Unique NK Cell Subset with Immunomodulatory Potential. J Exp Med. 2003;198(8):1201-12.

35. Wilk E, Kalippke K, Buyny S, Schmidt RE, Jacobs R. New aspects of NK cell subset identification and inference of NK cells' regulatory capacity by assessing functional and genomic profiles. Immunobiology. 2008;213(34):271-83

36. Zieker D, Fehrenbach E, Dietzsch J, Fliegner J, Waidmann M, Nieselt K, et al. CDNA microarray analysis reveals novel candidate genes expressed in human peripheral blood following exhaustive exercise. Physiol Genomics. 2005;23(3):287-94

37. McHale CM, Zhang L, Hubbard AE, Zhao X, Baccarelli A, Pesatori AC, et al. Microarray analysis of gene expression in peripheral blood mononuclear cells from dioxin-exposed human subjects. Toxicology. 2007;229(1-2):101-13.

38. Marçais A, Viel S, Grau M, Henry T, Marvel J, Walzer T. Regulation of mouse NK cell development and function by cytokines. Front Immunol. 2013;4:450.

39. Schindler C, Levy DE, Decker T. JAK-STAT signaling: from interferons to cytokines. J Biol Chem. 2007;282(28):20059-63.

40. Hanna J, Wald O, Goldman-Wohl D, Prus D, Markel G, Gazit R, et al. CXCL12 expression by invasive trophoblasts induces the specific migration of CD16human natural killer cells. Blood. 2003;102(5):1569-77.

41. Mallone R, Funaro A, Zubiaur M, Baj G, Ausiello CM, Tacchetti C, et al. Signaling through CD38 induces NK cell activation. Int Immunol. 2001:13(4):397-409.

42. Deaglio S, Zubiaur M, Gregorini A, Bottarel F, Ausiello CM, Dianzani U, et al Human CD38 and CD16 are functionally dependent and physically associated in natural killer cells. Blood. 2002;99(7):2490-8.

43. Li P, Spolski R, Liao W, Wang L, Murphy TL, Murphy KM, et al. BATF-JUN is critical for IRF4-mediated transcription in T cells. Nature. 2012;490(7421):543-6.

44. Tussiwand R, Lee WL, Murphy TL, Mashayekhi M, KC W, Albring JC, et al. Compensatory dendritic cell development mediated by BATF-IRF interactions. Nature. 2012:490(7421):502-7.

45. Hughes T, Briercheck EL, Freud AG, Trotta R, McClory S, Scoville SD, et al. The transcription Factor AHR prevents the differentiation of a stage 3 innate lymphoid cell subset to natural killer cells. Cell Rep. 2014;8(1):150-62. 
46. Wendt K, Wilk E, Buyny S, Schmidt RE, Jacobs R. Interleukin-21 differentially affects human natural killer cell subsets. Immunology. 2007;122(4):486-95.

47. Roda JM, Parihar R, Lehman A, Mani A, Tridandapani S, Carson 3rd WE. Interleukin-21 enhances NK cell activation in response to antibody-coated targets. J Immunol. 2006;177(1):120-9.

48. Gabrilovich DI, Nagaraj S. Myeloid-derived suppressor cells as regulators of the immune system. Nat Rev Immunol. 2009;9(3):162-74.

49. Li H, Han Y, Guo Q, Zhang M, Cao X. Cancer-expanded myeloid-derived suppressor cells induce anergy of NK cells through membrane-bound TGF-beta 1. J Immunol. 2009;182(1):240-9.

50. Parker KH, Sinha P, Horn LA, Clements VK, Yang H, Li J, et al. HMGB1 enhances immune suppression by facilitating the differentiation and suppressive activity of myeloid-derived suppressor cells. Cancer Res. 2014;74(20):5723-33.

51. Beury DW, Parker KH, Nyandjo M, Sinha P, Carter KA, Ostrand-Rosenberg S. Cross-talk among myeloid-derived suppressor cells, macrophages, and tumor cells impacts the inflammatory milieu of solid tumors. J Leukoc Biol. 2014;96(6):1109-18.

52. Mundy-Bosse BL, Young GS, Bauer T, Binkley E, Bloomston M, Bill MA, et al. Distinct myeloid suppressor cell subsets correlate with plasma IL-6 and IL-10 and reduced interferon-alpha signaling in $\mathrm{CD}^{+} \mathrm{T}$ cells from patients with Gl malignancy. Cancer Immunol Immunother. 2011;60(9):1269-79.

53. Carson WE, Lindemann MJ, Baiocchi R, Linett M, Tan JC, Chou CC, et al. The functional characterization of interleukin-10 receptor expression on human natural killer cells. Blood. 1995;85(12):3577-85.

54. Kohanbash G, McKaveney K, Sakaki M, Ueda R, Mintz AH, Amankulor N, et al. GM-CSF promotes the immunosuppressive activity of glioma-infiltrating myeloid cells through interleukin-4 receptor-a. Cancer Res. 2013;73(21):6413-23.

55. Sade-Feldman M, Kanterman J, Ish-Shalom E, Elnekave M, Horwitz E, Baniyash M. Tumor necrosis factor-a blocks differentiation and enhances suppressive activity of immature myeloid cells during chronic inflammation. Immunity. 2013;38(3):541-54.

56. Lee JM, Seo JH, Kim YJ, Kim YS, Ko HJ, Kang CY. Agonistic Anti-CD137 Monoclonal Antibody Treatment Induces CD11bGr-1 Myeloid-derived Suppressor Cells. Immune Netw. 2010;10(3):104-8.

57. Kohrt HE, Colevas AD, Houot R, Weiskopf K, Goldstein MJ, Lund P, et al. Targeting CD137 enhances the efficacy of cetuximab. J Clin Invest. 2014;124(6):2668-82

58. Eruslanov E, Stoffs T, Kim WJ, Daurkin I, Gilbert SM, Su LM, et al. Expansion of CCR8(+) inflammatory myeloid cells in cancer patients with urothelial and renal carcinomas. Clin Cancer Res. 2013;19(7):1670-80.

59. Grangeiro De Carvalho E, Bonin M, Kremsner PG, Kun JF. Plasmodium falciparum-infected erythrocytes and IL-12/IL-18 induce diverse transcriptomes in human NK cells: IFN- $\alpha / \beta$ pathway versus TREM signaling PLoS One. 2011;6(9):e24963.

60. Palacios R, Goni J, Martinez-Forero I, Iranzo J, Sepulcre J, Melero I, et al. A network analysis of the human T-cell activation gene network identifies JAGGED1 as a therapeutic target for autoimmune diseases. PLoS One. 2007;2(11):e1222

61. Gupta S, Ellis SE, Ashar FN, Moes A, Bader JS, Zhan J, et al. Transcriptome analysis reveals dysregulation of innate immune response genes and neuronal activity-dependent genes in autism. Nat Commun. 2014;5:5748.

62. Meehan TF, Vasilevsky NA, Mungall CJ, Dougall DS, Haendel MA, Blake JA, et al. Ontology based molecular signatures for immune cell types via gene expression analysis. BMC Bioinform. 2013;14:263.

63. Smith MA, Maurin M, Cho HI, Becknell B, Freud AG, Yu J, et al. PRDM1/ Blimp-1 controls effector cytokine production in human NK cells. J Immunol. 2010;185(10):6058-67.

64. Heng TS, Painter MW, Consortium IGP. The Immunological Genome Project: networks of gene expression in immune cells. Nat Immunol. 2008;9(10):1091-4.

65. Xue J, Schmidt SV, Sander J, Draffehn A, Krebs W, Quester I, et al. Transcriptome-based network analysis reveals a spectrum model of human macrophage activation. Immunity. 2014;40(2):274-88.

66. Bezman NA, Kim CC, Sun JC, Min-Oo G, Hendricks DW, Kamimura Y, et al. Molecular definition of the identity and activation of natural killer cells. Nat Immunol. 2012;13(10):1000-9.

\section{Submit your next manuscript to BioMed Central and take full advantage of:}

- Convenient online submission

- Thorough peer review

- No space constraints or color figure charges

- Immediate publication on acceptance

- Inclusion in PubMed, CAS, Scopus and Google Scholar

- Research which is freely available for redistribution 